Revista Economía y Administración, Vol. 9, No. 1, 2018

\title{
ESTRUCTURA DE LA RECAUDACIÓN FISCAL EN HONDURAS: PROGRESIVO O REGRESIVO
}

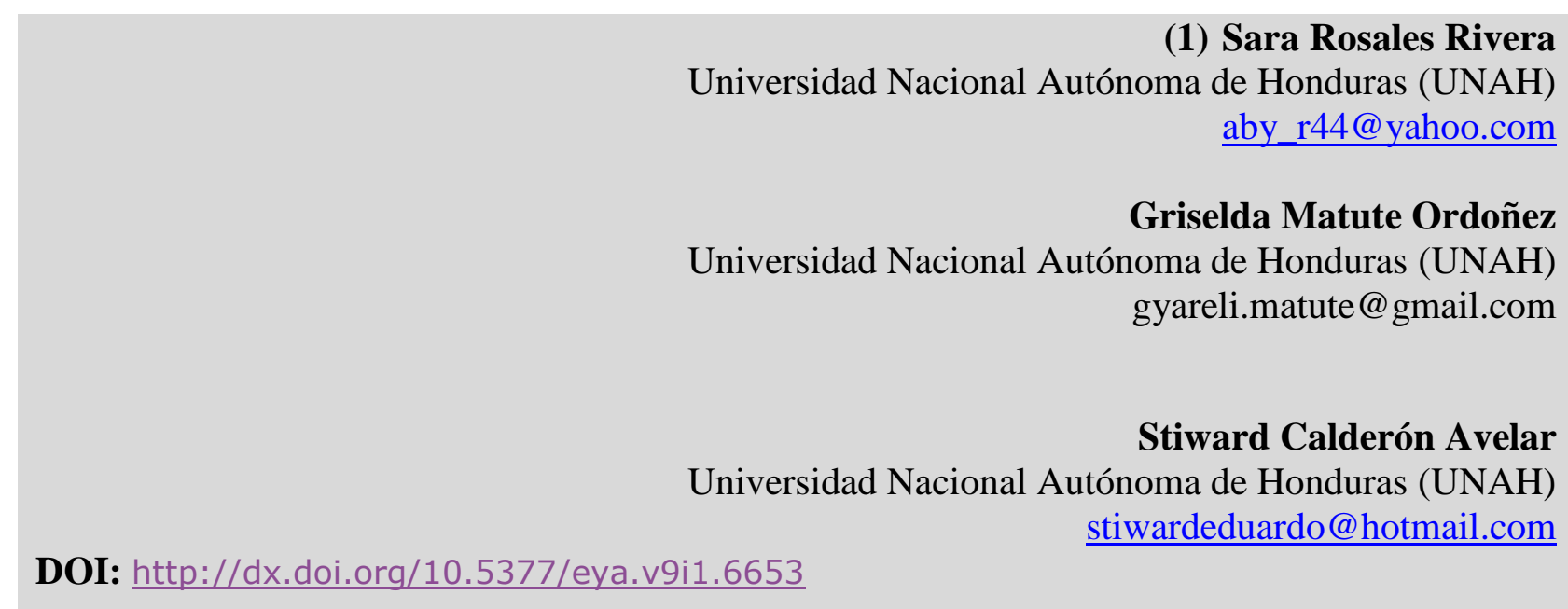

\section{RESUMEN}

El propósito de la presente investigación técnica es hacer un análisis del comportamiento de los ingresos fiscales durante el periodo 2000-2015 de los países centroamericanos, principalmente Honduras. Se espera que el lector adquiera un panorama más amplio de la importancia de los ingresos tributarios en el país y de los países de la región.

Palabras clave: Progresividad,

Regresividad, Impuestos

(1) Autor de contacto 
Revista Economía y Administración, Vol. 9, No. 1, 2018

\title{
STRUCTURE OF FISCAL COLLECTION IN HONDURAS: PROGRESSIVE OR REGRESSIVE
}

\begin{abstract}
(1) Sara Rosales Rivera
Universidad Nacional Autónoma de Honduras (UNAH) aby_r44@yahoo.com

Griselda Matute Ordoñez

Universidad Nacional Autónoma de Honduras (UNAH) gyareli.matute@gmail.com

Stiward Calderón Avelar Universidad Nacional Autónoma de Honduras (UNAH) stiwardeduardo@hotmail.com

DOI: http://dx.doi.org/10.5377/eya.v9i1.6653
\end{abstract}

\begin{abstract}
The purpose of this technical research is to analyze the behavior of fiscal revenues during the period 2000-2015 of the Central American countries, mainly Honduras. It is expected that the reader will acquire a broader picture of the importance of tax revenues in the country and in the countries of the region.
\end{abstract}

Keywords: Progressivity, Regression, Taxes

(1) Corresponding author 


\section{ESTRUCTURA DE LA RECAUDACIÓN FISCAL EN HONDURAS: PROGRESIVO O REGRESIVO}

Revista Economía y Administración, Vol. 9, No. 1, 2018

ingresos tributarios del total de los

\section{INTRODUCCIÓN}

El presente documento hace un análisis del comportamiento de los ingresos fiscales en Centroamérica y da a conocer la estructura de la recaudación fiscal y la trayectoria que siguen los ingresos tributarios en Honduras durante el periodo 2000-2015.

Es importante conocer las medidas adoptadas por el Gobierno para contrarrestar los efectos causados tanto por la crisis financiera mundial y la crisis política por la que atravesó la economía hondureña. También se analiza la estructura y tendencias de la recaudación de los principales impuestos en Honduras, así como una comparación de la trayectoria que siguen los impuestos tributarios en toda la región centroamericana.

El siguiente informe cuenta con dos secciones. En la primera sección se describen las generalidades de la región centroamericana, en donde se observa la débil recuperación que mostro la presión tributaria y las finanzas públicas de los estados centroamericanos después de la crisis financiera global. Además, se realiza un análisis de cuanto representan los ingresos totales. En ese mismo apartado se describe la evolución que ha tenido la presión tributaria en Honduras. Igualmente se hace mención a la caracterización del sector fiscal hondureño y como este está estructurado. Adicionalmente se realiza una estimación de la inversión que hace el Gobierno en dos de las áreas que contribuyen al desarrollo económico de un país como lo son educación y salud en función de los ingresos tributarios. Asimismo, se describen las leyes y reformas tributarias que se implementaron para subsanar las finanzas del Estado de Honduras.

En la segunda sección se presenta el análisis de los resultados de los datos obtenidos de los diferentes ministerios y secretarias de Estado. Además, se explica la trayectoria que mantienen los impuestos directos e indirectos y se hace énfasis en los principales impuestos que generan mayores ingresos tributarios. Finalmente, se muestran las debilidades y fortalezas que presenta el sistema tributario hondureño. 


\section{ESTRUCTURA DE LA RECAUDACIÓN FISCAL EN HONDURAS: PROGRESIVO O REGRESIVO}

Revista Economía y Administración, Vol. 9, No. 1, 2018

\section{GENERALIDADES}

\subsection{Generalidades en Centroamérica}

En los últimos años las presiones tributarias de los países de la región Centroamericana han presentado un crecimiento progresivo, a excepción del año 2009 producto de los efectos de la crisis financiera global, la cual impacto negativamente el comercio, generando una disminución en los ingresos provenientes de dicha actividad (Secretaria de Finanzas, 2009). Se tradujo en una reducción en la presión tributaria principalmente en Honduras (1.9\%), Costa Rica (1.8\%), Guatemala (1.2\%), y El Salvador (0.9\%). Por otra parte, Nicaragua presento una contracción en su presión tributaria de $0.2 \%$ y Panamá mantuvo un nivel de recaudación constante. Luego del año 2009 el promedio de la presión tributaria de la región presento un ritmo creciente, siendo el determinante principal las diversas reformas y leyes establecidas durante los últimos años.

\section{Presión tributaria}

En la figura No. 1 se observa la presión tributaria de los países centroamericanos, siendo Honduras el que ha presentado la mayor recaudación tributaria a través de los años, alcanzando niveles de $16.4 \%$. Caso contrario es el de Panamá y Guatemala, los cuales muestran los niveles más bajos de toda la región de $8.2 \%$ y $9.4 \%$, respectivamente.

Figura No. 1 Presión Tributaria

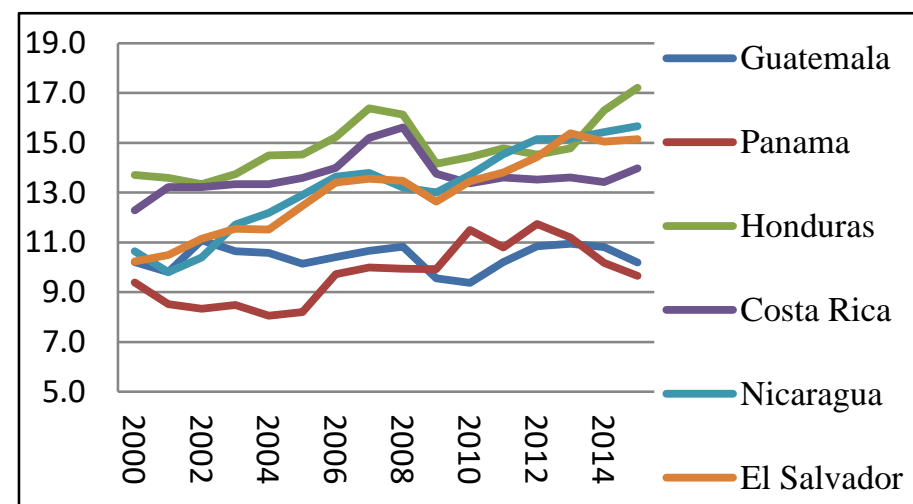

Fuente: Elaboración propia con datos de CEPAL, SEFIN, $\mathrm{BCH}, \mathrm{BCR}$, Ministerio de Economía y Finanzas, Ministerio de Hacienda El Salvador, Banco Mundia, Ministerio de Hacienda Costa Rica y Banco Central de Guatemala

Las favorables condiciones macroeconómicas que presentaba la región centroamericana durante el periodo 2000-2008, pueden ser explicadas como resultado del tratado comercial firmado 


\section{ESTRUCTURA DE LA RECAUDACIÓN FISCAL EN HONDURAS: PROGRESIVO O REGRESIVO}

Revista Economía y Administración, Vol. 9, No. 1, 2018

por el bloque centroamericano con los

Estados Unidos, el cual dinamizo las economías de la región (Ministerio de Comercio Exterior, 2004). Este fortalecimiento de las economías de la región centroamericana genero un comportamiento creciente en la presión tributaria. Asimismo, previo a la crisis financiera global del 2008, el Banco Interamericano de Desarrollo aprobó un alivio de Deuda para 5 países Latinoamericanos que presentaban altos índices de pobreza, entre los cuales se encontraban Honduras y Nicaragua. Este alivio de la deuda externa resultó en un ascenso significativo de las presiones tributarias de estos países. (Gobierno de Reconciliación y Unidad Nacional, 2007)

Luego de la crisis de 2009 todos los países centroamericanos presentaron una ralentización de su carga tributaria, a excepción de Panamá que mantuvo una tendencia estable de $9.9 \%$ en cuanto a su presión tributaria. Economías como Nicaragua y El Salvador fueron los países que mejor se recuperaron después de la crisis, gracias a diversas leyes y reformas adoptadas, mientras tanto Honduras, Costa Rica y Panamá mantuvieron flujos de ingresos tributarios moderados durante la postcrisis. En 2013 la presión tributaria en Honduras tuvo un alza, debido a la aprobación de la ley de ordenamiento de las finanzas públicas y el cobro del impuesto sobre venta el cual paso del $12 \%$ a $15 \%$, generando un aumento de la recaudación tributaria, pasando de $14.8 \%$ en el 2013 a un $16.3 \%$ y $17.2 \%$ en los años del 2014 y 2015, respectivamente (Ley de ordenamiento de las finanzas públicas, control de las exoneraciones y medidas anti evasión, 2013), posicionando a Honduras como el país con la mayor recaudación tributaria de la región centroamericana.

La figura No. 2 muestra los ingresos tributarios como porcentaje de los gastos totales, estos han mostrado un comportamiento estable a través de los años para la mayoría de los países de la región centroamericana. Cabe destacar que Panamá presenta la menor proporción (43\%), lo cual implica que a principios de los años analizados se destinaba menos de la mitad de la recaudación tributaria al gasto público. Sin embargo, desde 2005 los niveles de ingresos tributarios como porcentaje del gasto del Gobierno General han aumentado, resultado del gasto en 


\section{ESTRUCTURA DE LA RECAUDACIÓN FISCAL EN HONDURAS: PROGRESIVO O REGRESIVO}

Revista Economía y Administración, Vol. 9, No. 1, 2018

proyectos dirigidos a disminuir la pobreza (La Prensa, 2015).

Figura No. 2 Ingresos tributarios en función de los gastos totales del sector público.

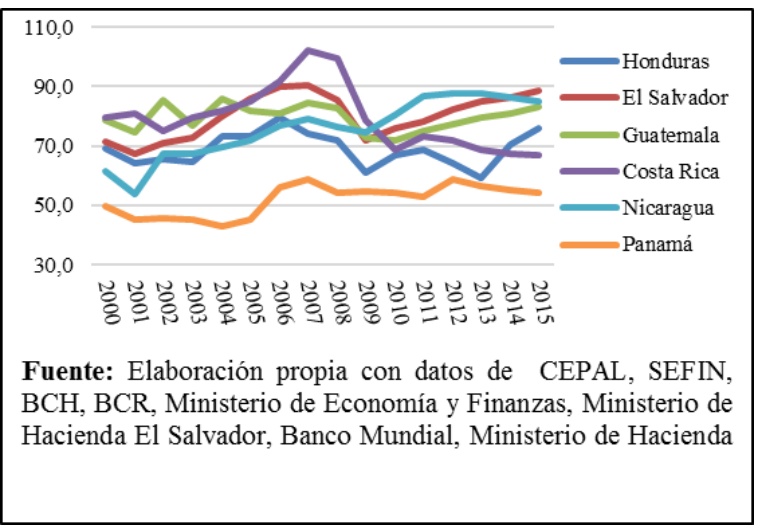

Asimismo, Costa Rica tuvo un comportamiento creciente en los primeros 6 años de la década, llegando a alcanzar un $102.0 \%$ de los ingresos tributarios con respecto al gasto para el 2007. Es decir, que la recaudación tributaria no llego a cubrir los gastos públicos. A la vez, se puede mencionar que para los años 2008 y 2009, los efectos negativos de la crisis financiera global repercutieron en una desaceleración en las economías de los países centroamericanos. (Stiftung, 2010) Esta desaceleración, dio como resultado una baja recaudación tributaria, lo que a su vez produjo que los países
Centroamericanos disminuyeran sus ingresos tributarios como proporción de los gastos públicos.

Figura No. 3 Ingresos tributarios en función de los ingresos totales del Sector Público.

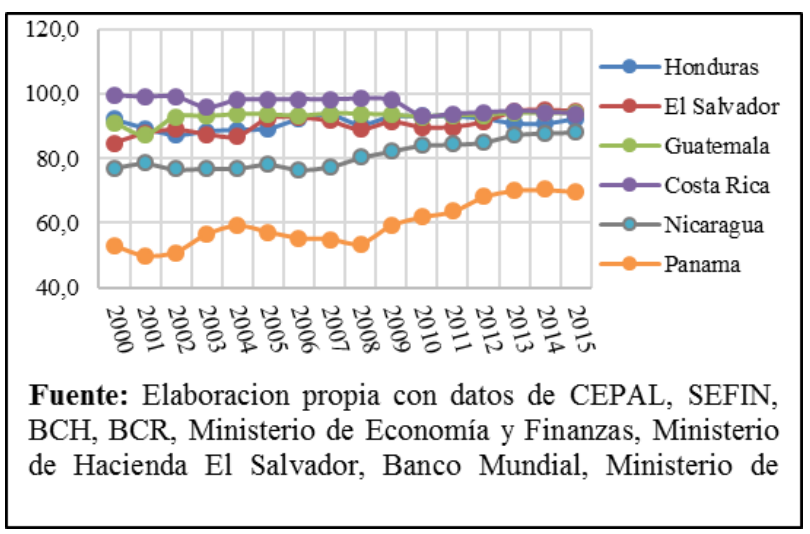

Los ingresos tributarios son una de las principales fuentes de ingreso para los gobiernos. La figura No. 3 se aprecia que los ingresos tributarios en función de los ingresos totales de los gobiernos representan más del $75 \%$ para la mayoría de los países, con la excepción de Panamá cuyo ingreso tributario se ha mantenido en un rango $45 \%-70 \%$.

Asimismo, los ingresos tributarios de Costa Rica han constituido más del $90 \%$ del total de sus ingresos. Siendo el país con mayor recaudación tributaria como porcentaje de los ingresos totales. Tales 


\section{ESTRUCTURA DE LA RECAUDACIÓN FISCAL EN HONDURAS: PROGRESIVO O REGRESIVO}

Revista Economía y Administra

niveles de recaudación se han logrado obtener por la implementación de medidas, reformas y leyes aprobadas por los distintos países de la región para incrementar sus bases tributarias, resultando en una mayor representación de los ingresos tributarios sobre el total de los ingresos totales del Sector Público para todos los países de la región centroamericana. (Icefi, 2014).

Figura No. 4 Evolución de la presión tributaria en Honduras

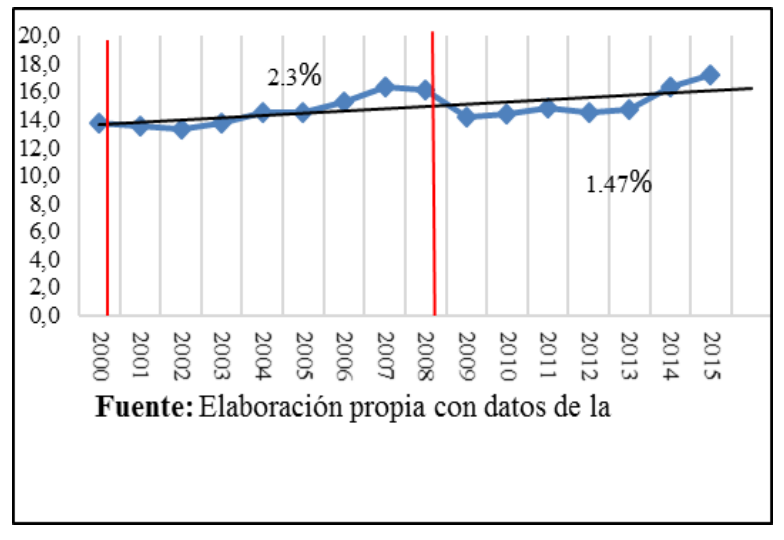

En la figura No. 4 se observa que durante el periodo 2000-2008 Honduras presentó un ascenso en la presión tributaria como porcentaje PIB, aumento con una tasa de la presión tributaria de $2.3 \%$ por las favorables condiciones macroeconómicas por las que pasaba el país, ya que para esta época la economía presento un crecimiento económico de más del 6\%.
La llegada de la crisis financiera mundial provocó una caída en los ingresos fiscales como consecuencia de la disminución de las importaciones y una baja en la actividad económica interna que impacto negativamente en la recaudación del impuesto sobre ventas (Secretaria de Finanzas, 2009).

Otro hecho que estimulo el debilitamiento de los ingresos tributarios fue la crisis política ocurrida en el 2009 generando que los ingresos tributarios disminuyeran. Cabe destacar que para el 2010 los ingresos fiscales mostraron una leve recuperación. En este mismo año se dio la implementación de "La Ley de Fortalecimiento de Ingresos, Equidad Social y Racionalización del Gasto Público" como una medida de emergencia para estabilizar la economía. Después de la crisis tanto política como económica que atravesó el país se implementaron distintas medidas y reformas con el propósito de estabilizar la situación financiera, sin embargo, aunque los ingresos tributarios presentaron un aumento, no se logró tener un crecimiento sostenido del PIB. Fue hasta a partir del 2013 que se generó un aumento significativo en la tasa de presión tributaria. 


\section{ESTRUCTURA DE LA RECAUDACIÓN FISCAL EN HONDURAS: PROGRESIVO O REGRESIVO}

Revista Economía y Administración, Vol. 9, No. 1, 2018

Figura No. 5 Caracterización del sector fiscal en Honduras

I00\% $25 \%$
$90 \%$
$85 \%$
$80 \%$

Los ingresos totales del sector fiscal en Honduras se comprenden por: ingresos tributarios, ingresos no tributarios, ingresos de capital y desde el año 2012 por la tasa de seguridad que cobra el Estado.

En la figura No. 5 se observa que los ingresos tributarios han sido el ingreso más importante que capta el Estado de Honduras, llegando a alcanzar proporciones de hasta el $92 \%$ de los ingresos totales y siendo como mínimo un $87 \%$ de dichos ingresos. A la vez este ingreso está compuesto por impuestos directos, impuestos indirectos y los servicios de actividades especiales. Asimismo, los ingresos tributarios han tenido un comportamiento creciente, pasando de L. 14,600.4 millones en el año 2000 a L. 77,673.0 en el año 2015. Cabe recalcar que los ingresos tributarios están comprendidos en su mayoría por impuestos sobre la renta e impuestos sobre la venta que son los que generan mayores ingresos al país.

También es importante mencionar que los ingresos no tributarios son una fuente importante de ingresos, pero en menor proporción que los ingresos tributarios. A su vez los ingresos no tributarios están comprendidos por tasas y tarifas, transferencias al sector público, cánones por concesiones, entre otros. Asimismo, estos ingresos han mantenido una recaudación creciente, los cuales se han encontrado desde L. 1241.1millones en el 2000, hasta un máximo de L. 4,516.4 en el 2008, después de este periodo presentaron una caída como resultado de acontecimientos externos. Sin embargo, para el año 2015 se logró una recaudación de ingresos no tributarios de L. 4,256.0 millones.

Cabe destacar que los ingresos de capital han sido un monto poco representativo en los ingresos totales puesto que solo se recaudaron en los años 2000, 2001, 2004 y 2005 siendo de L. 10.5, L. 31.4, L. 129.9 y L.131.8 millones respectivamente. 


\section{ESTRUCTURA DE LA RECAUDACIÓN FISCAL EN HONDURAS: PROGRESIVO O REGRESIVO}

Revista Economía y Administración, Vol. 9, No. 1, 2018

Además, en el año 2012 se implementó la tasa de seguridad con el fin de destinar más recursos para el combate de la criminalidad e inseguridad del país. Siendo estos ingresos aplicados a cuentas bancarias que tengan un monto mayor a L. 120,000.00. (Tasa de Seguridad Poblacional, 2016).

Estructura de los ingresos tributarios, durante la última década la estructura de los ingresos tributarios de Honduras está compuesta principalmente por impuestos directos e indirectos, los cuales han mostrado variaciones en los niveles de recaudación tributaria del país. Como se observa en la figura 8 los impuestos con mayor recaudación son los impuestos a la renta, producción, consumo y ventas, siendo estos tres últimos partes de los impuestos indirectos.

Figura No. 6 Estructura de los ingresos tributarios.

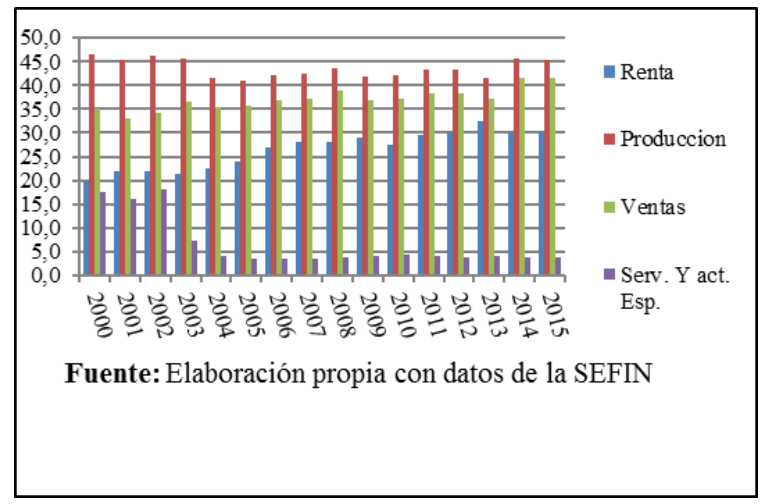

Es importante mencionar que los impuestos a la producción y ventas son los que representan la mayor recaudación de ingresos en el sistema tributario, con un promedio de $44 \%$ en los impuestos sobre la producción y un $27 \%$ en el impuesto sobre la renta. Cabe destacar que el impuesto sobre servicios y actividades específicas tenía un crecimiento ascendente, pero para el 2004 bajo drásticamente, como consecuencia del Decreto 19-2003, que consolidó en un solo impuesto dolarizado, los tres gravámenes que recaían sobre los carburantes derivados del petróleo. Este nuevo impuesto paso a conocerse como el impuesto al aporte social y vial.

Por lo tanto, los impuestos tradicionales de servicios y actividades solo agrupan (Timbres de Vehículos, Gravámenes de Servicios Turísticos y Licencias) (Secretaria de Finanzas, 2004).

Respecto al impuesto sobre la renta, este ha presentado una trayectoria ascendente durante los años, salvo en el 2010 como resultado del cobro a las utilidades obtenidas durante el año anterior. En cuanto a los impuestos sobre la 


\section{ESTRUCTURA DE LA RECAUDACIÓN FISCAL EN HONDURAS: PROGRESIVO O REGRESIVO}

Revista Economía y Administración, Vol. 9, No. 1, 2018

producción, consumo y ventas para el año

2013 tuvieron uno de los niveles más bajos de percepción durante los últimos 15 años, puesto que el impuesto sobre ventas fue impactado negativamente por el elevado índice de evasión fiscal y el gran número de contribuyentes que gozaban de exoneraciones. Además del poco crecimiento de los impuestos a las bebidas alcohólicas y gaseosas. (Secretaria de Finanzas, 2014).

\section{Leyes y reformas fiscales en Honduras}

Ley de fortalecimiento de los ingresos, equidad social y racionalización del gasto público (decreto N. 17 2010). Esta ley fue creada teniendo como base primordial; reformar el sistema de recaudación tributaria, logrando una eficiente recaudación de los ingresos fiscales, con el fin de mejorar la transparencia y equidad tributaria mediante la ampliación de la base tributaria, eliminando las exoneraciones y privilegios fiscales a personas naturales y jurídicas. Las disposiciones que se efectuaron con esta ley estaban orientadas a mejorar las finanzas públicas y racionalizar el gasto público mediante el fortalecimiento del sistema tributario hondureño por medio del impuesto sobre renta (ISR) y el impuesto sobre venta (ISV) (Ley de fortalecimiento de los ingresos, equidad social y racionalización del gasto público, 2010).

La tasa del 1\% (Decretos 42-2011). El propósito de esta reforma era evitar prácticas de evasión y omisión tributaria, como producto de la debilidad en las normas tributarias, también establece que es de interés nacional crear mecanismos de fortalecimiento en el régimen fiscal. Igualmente, esta reforma tiene como objetivo que las personas naturales y jurídicas paguen el 1\% sobre los ingresos brutos del periodo impositivo, cabe mencionar que los contribuyentes que operen con precios regulados pagaran una tasa de $0.5 \%$. (Ley de medida antievasión en el impuesto sobre la renta, 2012)

Ley de Eficiencia en los Ingresos y el Gasto Público (Decreto 113-2011). Esta ley procura mantener la eficiencia en los ingresos mediante el control y restricción de exoneraciones y medidas anti-evasión; así como el control del gasto público para absorber recursos que se destinen a programas sociales en el marco del Plan visión de País. Este estatuto se enfoca 


\section{ESTRUCTURA DE LA RECAUDACIÓN FISCAL EN HONDURAS: PROGRESIVO O REGRESIVO}

Revista Economía y Administración, Vol. 9, No. 1, 2018

principalmente en la devolución del ISV

por compras con tarjetas de débito o

crédito, ya que las personas que adquieran bienes o servicios tendrán derecho a la devolución del ocho por ciento $(8 \%)$ del importe del impuesto efectivamente pagado. (Ley de medida anti-evasión en el impuesto sobre la renta, 2012)

Ley de Medida Anti-Evasión en el Impuesto sobre la Renta, Decreto No.962012). Este régimen establece que se deberá hacer un pago anticipado del impuesto sobre renta (ISR) para aquellos contribuyentes que no estén inscritos en el registro de contribuyentes de la Dirección Ejecutiva de Ingresos (DEI). (Ley de medida anti-evasión en el impuesto sobre la renta, 2012)

Prórrogas de la amnistía fiscal (Decretos 260-2011). El objetivo de esta ley es que todos los contribuyentes se mantengan al día con sus obligaciones tributarias. Por consiguiente, el Estado deberá dar facilidades con el propósito que los mismos puedan cumplir con sus deberes tributarios.

Ley de ordenamiento de las finanzas públicas, control de las exoneraciones y medidas anti-evasión decreto N. 278-
2013.La implementación de esta ley tenía como objetivo regular las exoneraciones otorgadas en el impuesto sobre renta, en el impuesto sobre ventas y en el derecho arancelario a la importación con la intención de hacer más eficiente la economía y mejorar el bienestar de los sectores más pobres de la población, construyendo una sociedad más justa y equitativa. (Ley de ordenamiento de las finanzas públicas, control de las exoneraciones y medidas anti-evasión, 2013).

\section{ANÁLISIS DE RESULTADOS}

Cada país de la región se caracteriza por tener sistemas tributarios diferentes. Unos se inclinan por ser más progresivos, otros por ser más regresivos. Es decir que sus bases tributarias se especializan en recaudar más impuestos directos o indirectos.

Figura No. 7 Ingresos directos e indirectos de los países Centroamericanos 


\section{ESTRUCTURA DE LA RECAUDACIÓN FISCAL EN HONDURAS: PROGRESIVO O REGRESIVO}

Revista Economía y Administración, Vol. 9, No. 1, 2018

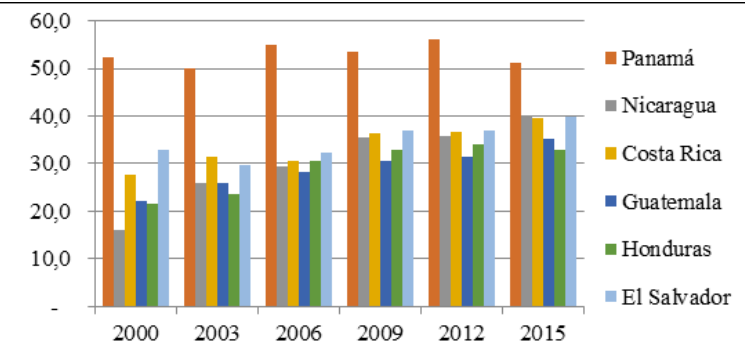

Fuente: Elaboración propia con datos de CEPAL, SEFIN, $\mathrm{BCH}, \mathrm{BCR}$, Ministerio de Hacienda El Salvador, Ministerio de Economía y Finanzas, Banco Mundial, Ministerio de

En la figura No. 7 se observa la trayectoria que han tenido los impuestos directos de la región centroamericana durante los últimos años. El país que más destaca es Panamá, ya que sus impuestos directos en el año 2000 ascendieron a 52.3\%, seguido de la economía salvadoreña que en ese mismo año sus impuestos directos ascendieron a $32.9 \%$ y siendo Nicaragua el de menor recaudación con un $16.1 \%$.

En el transcurso de los años los impuestos directos en la región centroamericana han sido muy volátiles. Cabe destacar que para el año 2006, los impuestos directos en la economía panameña ascendieron a $55 \%$ mostrando un aumento de $2.8 \%$ en 6 años, dicho aumento se debe a las altas tasas de crecimiento que ha gozado este país.
Caso contrario es el Salvador ya que sus impuestos directos disminuyeron en $0.4 \%$ debiéndose esto al bajo crecimiento económico. Nicaragua registro un aumento de $13.3 \%$ como producto del alivio de la deuda externa, representando la tasa más alta de la región durante los últimos 6 años. La mayoría de las reformas realizadas en Centroamérica estaban encaminadas a modificar el impuesto sobre renta (ISR), las evasiones fiscales, la modificación de tasas imponibles $\mathrm{y}$ reformar el impuesto al valor agregado (IVA).

Figura No. 8 Ingresos directos

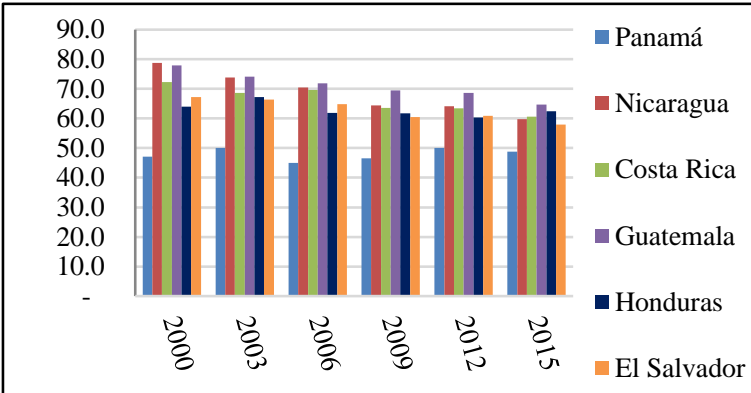

Fuente: Elaboración propia con datos de CEPAL, SEFIN, BCH, BCR, Ministerio de Hacienda El Salvador, Ministerio de Economía y Finanzas,

Los países centroamericanos se han caracteriza por mantener altos índices de impuestos indirectos, siendo estos los que 


\section{ESTRUCTURA DE LA RECAUDACIÓN FISCAL EN HONDURAS: PROGRESIVO O REGRESIVO}

Revista Economía y Administración, Vol. 9, No. 1, 2018

representan mayores fuentes de ingresos en las economías, a excepción de Panamá ya que sus ingresos fiscales se concentran en impuestos directos. En la figura 10 se aprecia que en el cierre del 2000 la economía nicaragüense presento los niveles más altos de ingresos indirectos con un $78.7 \%$ como porcentaje de los ingresos tributarios y en último se encuentra Panamá con 47\%. En los últimos años debido a los cambios estructurales y la implementación de reformas, los ingresos directos se han mantenido relativamente estables.

Asimismo, se debe mencionar que los ingresos indirectos se concentran en impuestos al consumo y el uso de bienes y servicios, generando un gran impacto en el bolsillo de los que presentan menores ingresos. La regresividad o progresividad de los ingresos fiscales de un país se debe a la ponderación que se le da a los impuestos directos e indirectos. (Escobar, 2010).

Figura No. 9 Comportamiento de los impuestos directos e indirectos

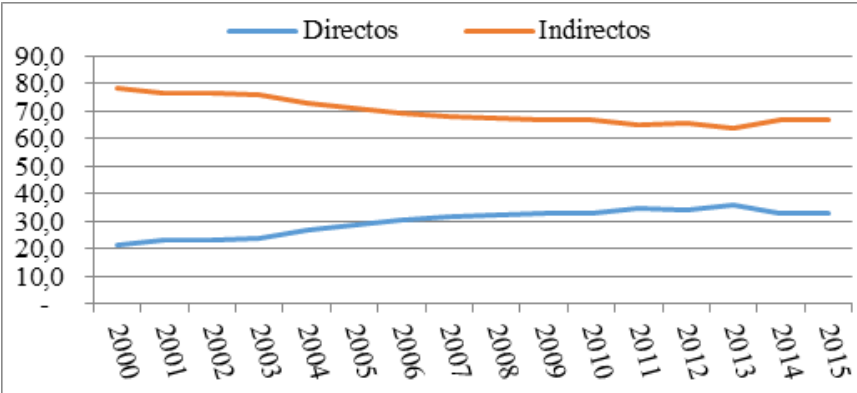

Fuente: Elaboración propia con datos de la SEFIN

En la figura No. 9 se observa el comportamiento de los impuestos directos e indirectos a través de los años y como han ido ascendiendo o disminuyendo. Generalmente los impuestos indirectos son los de mayor recaudación en el país y los directos representan un porcentaje menor en comparación de los impuestos indirectos.

Asimismo, se debe aclarar que los impuestos directos son aquellos que se aplican sobre la manifestación directa de la riqueza, es decir, sobre el ingreso recibido por el individuo o empresa y sobre el patrimonio que cada uno tiene (casas, viviendas, etc.). Los impuestos indirectos, en cambio, se aplican sobre la manifestación indirecta de la riqueza, por ejemplo, el consumo, producción y ventas. (Escobar, 2010). 


\section{ESTRUCTURA DE LA RECAUDACIÓN FISCAL EN HONDURAS: PROGRESIVO O REGRESIVO}

Revista Economía y Administración, Vol. 9, No. 1, 2018

Cabe mencionar que las reformas fiscales

son las herramientas fundamentales para la generación de ingresos tributarios, ya sea por el lado de los impuestos directos o indirectos.

Es a partir del año 2003 que se obtuvo los mayores cambios en ambos tipos de impuestos, debido a que para dicho año se aprobaron y ejecutaron diversas reformas y leyes como la Ley de Equidad Tributaria, Ley de Racionalización de las Finanzas Públicas, Reforma del Código Tributario entre otras. (Secretaría de Estado en el Despacho de Finanzas,2012). Como resultado de esas reformas los impuestos directos se han incrementado de un promedio de $23 \%$ a un $34 \%$ para estos últimos años, en cambio los impuestos indirectos han presentado una disminución de un $75 \%$ a 64\%, desde el año 2000 a 2015. Claramente las medidas no han alcanzado lo estimado en el sistema tributario del país, de lograr disminuir esa diferencia en ambos tipos de impuestos.

En la figura No. 10 se observa el desglose de los impuestos indirectos de la economía hondureña. Con el propósito de comprender la importancia que se da a estos impuestos y observar el peso que representan en los impuestos indirectos.

Figura No. 10 Desglose de los impuestos indirectos

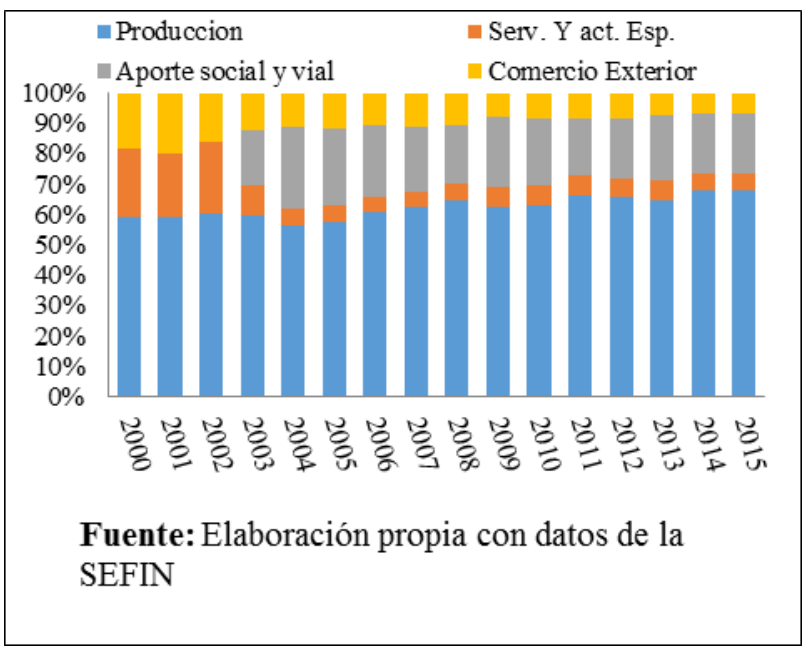

Los impuestos a la producción son los ingresos más importantes en los impuestos indirectos, este gravamen está compuesto a su vez por el impuesto sobre ventas, cervezas, cigarros, gaseosas, bebidas alcohólicas y otros. Estos en conjunto han representado más del $56 \%$ de los impuestos indirectos a lo largo de los años.

Para el año 2000 la recaudación por este impuesto era de $59.3 \%$, teniendo un comportamiento similar hasta el año 2004 en el cual presentó una leve disminución en este impuesto como resultado de un decremento en la producción de cerveza (1.9\%), por una disminución en la producción de gaseosas $(0.4 \%)$ y por un 


\section{ESTRUCTURA DE LA RECAUDACIÓN FISCAL EN HONDURAS: PROGRESIVO O REGRESIVO}

Revista Economía y Administración, Vol. 9, No. 1, 2018

pago realizado el año anterior por valores desfasados en concepto de impuestos en los cigarrillos. (Secretaria de Finanzas, 2004, pág. 59).

Después del año 2004 los impuestos sobre la producción recuperaron su tendencia creciente. En el año 2014, el impuesto sobre ventas fue reformado por medio del Decreto 278-2013, el cual incrementaba la tasa general de un $12 \%$ a un $15 \%$. Asimismo, aumento la tasa del impuesto sobre las bebidas alcohólicas, cigarros y cervezas del $15 \%$ al $18 \%$. Estas modificaciones aumentaron la recaudación del impuesto sobre la producción un $3.2 \%$ con respecto al año anterior. (Secretaria de Finanzas, 2015, pág. 103)

Los servicios y actividades especiales mostraban una recaudación de $22.5 \%$, $21.1 \%$ y 23.5, para los años 2000, 2001 y 2002 respectivamente. Sin embargo, a partir del año 2003 se dio una modificación en la clasificación de esta cuenta, separando los gravámenes que recaían sobre los carburantes derivados del petróleo de los impuestos. Es por esta razón que desde el año 2003 este impuesto representa una menor proporción en cuanto a los ingresos indirectos. (Secretaria de Finanzas, 2003, pág. 45). Mientras tanto, los impuestos al aporte social y vial han estado en un rango del $15 \%-25 \%$ de los impuestos indirectos, siendo el segundo impuesto que más contribuye a los impuestos indirectos.

Los impuestos al comercio exterior están comprendidos mayormente por impuestos a las importaciones, al petróleo y a otros impuestos que forman parte de transacciones con el exterior. Este impuesto represento una proporción significativa dentro de los impuestos indirectos durante el periodo del 20002002. Sin embargo, a partir del año 2003 se muestra una disminución producto que los impuestos sobre el petróleo ya no se contabilizaban como parte de los impuestos sobre el comercio exterior, sino que fue modificado para registrarlo en los impuestos al aporte social y vial. (Secretaria de Finanzas, 2005, pág. 60). Esta razón explica por qué para el año de 2003 muestra una disminución de 4.3\% con respecto al año anterior. A partir del año 2003, los impuestos sobre las importaciones han ido teniendo una leve recaída a lo largo de los años. 


\section{ESTRUCTURA DE LA RECAUDACIÓN FISCAL EN HONDURAS: PROGRESIVO O REGRESIVO}

Revista Economía y Administración, Vol. 9, No. 1, 2018

En la figura No. 11 se observa la descomposición de los impuestos directos como proporción de los ingresos tributarios. Con el fin de explicar cuáles son los principales impuestos que lo integran y observar las variaciones que han incurrido durante los años.

Figura No. 11 Descomposición de los impuestos directos

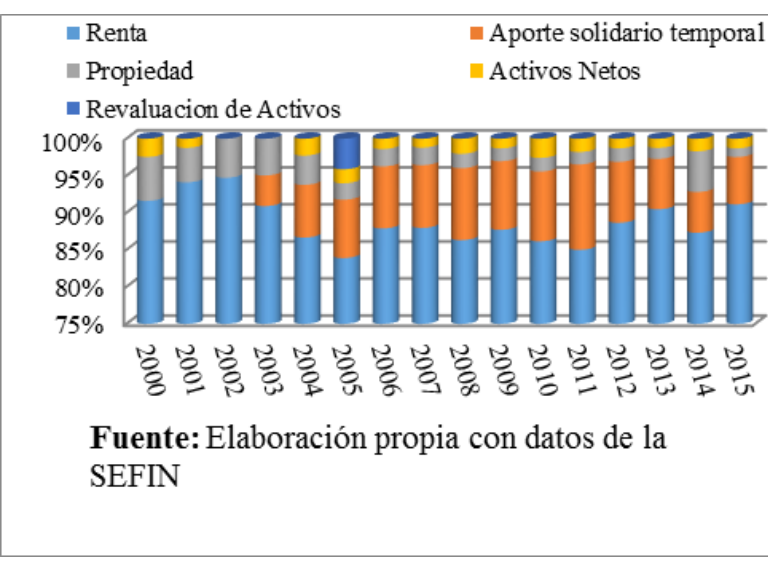

El impuesto sobre la renta ha sido el gravamen más importante de los impuestos directos, llegando a representar más del $80 \%$ del total de los impuestos directos. Sin embargo, ha mostrado fluctuaciones a través de los años. Durante el periodo 2000-2002 tuvo una tendencia creciente, pero para el año 2003 presento una caída debido a la creación del impuesto al aporte solidario temporal mediante decreto No. 51-2003 y el decreto no. 219-2003, con el propósito de un ordenamiento de las finanzas públicas. Este impuesto se aplica a las personas jurídicas que habiendo pagado el impuesto sobre la renta tengan más de L. 1, 000,000.00 en utilidades, el impuesto de aporte solidario corresponderá a un 5\% del monto de utilidades restantes.

El impuesto sobre la propiedad se aplica sobre los bienes y muebles de las personas naturales y jurídicas, este represento un aporte poco significativo para los años 2000-2004. Sin embargo, para los siguientes años la recaudación de este impuesto ha disminuido como resultado de las modificaciones en el Código Tributario, específicamente en la Ley de la Propiedad. Por otra parte, la revaluación de activos en el año 2005 representó el $4.1 \%$ de los ingresos directos. Este impuesto se aplica a las personas naturales o jurídicas que desean reevaluar los bienes 


\section{ESTRUCTURA DE LA RECAUDACIÓN FISCAL EN HONDURAS: PROGRESIVO O REGRESIVO}

Revista Economía y Administración, Vol. 9, No. 1, 2018

que conforman sus activos, el cual tendrá

que ser del $5 \%$ del monto recibido.

\section{Impuestos progresivos o regresivos en}

\section{Honduras}

El sistema tributario de Honduras se ha caracterizado por mantener altos niveles de recaudación por impuestos indirectos y a una menor proporción los impuestos directos. Es por medio de estos dos tipos de impuestos que se puede determinar si los impuestos son progresivos o regresivos del país. Pero antes se debe aclarar que son impuestos progresivos y regresivos. (Escobar, 2010, pág. 18)

Los impuestos progresivos se aplican a medida que mayor sea el ingreso, más alto será el cobro por impuestos. Lo que resulta que los impuestos progresivos reduzcan la recaudación sobre personas de ingresos menores, ya que ellos pagan un menor porcentaje sobre sus ganancias. Esto puede ser visto como algo bueno en sí mismo o puede ser hecho por razones pragmáticas, ya que requiere menores registros y complejidad para personas con menores negocios. (López Montiel, 2011)

En cambio, los impuestos regresivos son los que se aplican sin diferencia si el ingreso es mayor o menor siempre habrá un aumento de pago por impuestos. De acuerdo con López Montiel Los impuestos regresivos son utilizados por los estados en actividades en las que es de interés nacional el que se trabaje con grandes volúmenes de capital, por ejemplo, exportaciones con materia prima del país, combustibles, maderas exóticas, etc.

A partir de la información encontrada y el análisis de los datos se da a conocer que Honduras se caracteriza por mantener ingresos regresivos debido a que la mayor carga de los ingresos tributarios son los impuestos indirectos y en los impuestos específicos que gravan el consumo de las personas, independientemente de su nivel de ingreso. Mientras que los impuestos progresivos representan un porcentaje menor. Estos suelen ser impuestos a la renta ya sea a personas o empresas.

\section{CONCLUSIONES}

Los ingresos tributarios han sido la principal fuente de los ingresos totales del Sector Público de los países de la Región Centroamericana a través de los años. Los impuestos indirectos son los que más aportan a los ingresos tributarios en comparación a los impuestos directos, a excepción de Panamá cuyo 


\section{ESTRUCTURA DE LA RECAUDACIÓN FISCAL EN HONDURAS: PROGRESIVO O REGRESIVO}

Revista Economía y Administración, Vol. 9, No. 1, 2018

comportamiento de los impuestos directos

e indirectos ha sido el contrario. Es importante recalcar que la regresividad o progresividad de los ingresos fiscales se mide de acuerdo con la ponderación de impuestos directos e indirectos que recauda un país. Esto significa que la mayoría de los países centroamericanos se han caracterizado por tener estructuras tributarias regresivas, a excepción de Panamá ya que es la única economía centroamericana que percibe más impuestos directos lo que significa que tiene una estructura tributaria progresiva.

En el caso de Honduras, el sistema tributario está determinado por estar estructurado de forma regresiva, es decir que los impuestos indirectos representan una mayor carga en los ingresos tributarios. Uno de los problemas que está asociado a esta regresividad es que los impuestos indirectos afectan a gran parte de la población, como ser la clase media y pobre quienes son lo que más pagan impuestos de acuerdo con el ingreso que reciben. Se puede concluir que no se cumple la premisa básica fiscal, la cual indica que "el que más tiene, más debería pagar". La inversión en la secretaria de educación y salud con respecto a los ingresos tributarios ha presentado una disminución, trasladándose a otras secretarias.

\section{REFERENCIAS}

Escobar, L. E. (2010). Honduras: espacio fiscal para inversión social y productiva. Obtenido de http://www.undp.org/content/dam/ honduras/docs/publicaciones/HN_04 2010.pdf

Gobierno de Reconciliacion y Unidad Nacional. (2007). Programa economico financiero 2007-2010. Obtenido de http://www.bcn.gob.ni/publicacione s/periodicidad/eventual/PEF/PEF/PE F_2007-2010.pdf

Icefi. (2014). Centroamérica y las reformas fiscales recientes: logros, actores y desafíos para alcanzar un pacto fiscal. Obtenido de http://190.104.117.163/2014/julio/e sfinapub/contenido/ponencias/Euros ocial\%20II_reformas\%20fiscales\%20 CA_Jmenkos.pdf

Instituto Centroamericano de Estudios Fiscales. (2010). 2010: ¿El comienzo de la recuperación para Centroamérica? Obtenido de http://www.obela.org/system/files/L ente\%20Fiscal\%20Centroamericano \%20n\%C3\%BAm\%201\%20a\%C3\%B1o \%201_ICEFI_mayo\%202010.pdf

La Prensa. (2015). Presupuesto para 2016 destina $59 \%$ del gasto a 


\section{ESTRUCTURA DE LA RECAUDACIÓN FISCAL EN HONDURAS: PROGRESIVO O REGRESIVO}

Revista Economía y Administración, Vol. 9, No. 1, 2018

funcionamiento. Obtenido de

http://www.prensa.com/economia/

Presupuesto-destina-gasto-

funcionamiento_0_4265573596.html

Ley de fortalecimiento de los ingresos, equidad social y racionalizacion del gasto público. (22 de Abril de 2010). Diario Oficial la Gaceta. págs. A1-

A23.

Ley de medida antievasión en el impuesto sobre la renta. (20 de Julio de 2012). Diario Oficial la Gaceta. págs. A1-A3.

Ley de ordenamiento de las finanzas

públicas, control de las

exoneraciones y medidas

antievasión. (30 de Diciembre de 2013). Diario Oficial la Gaceta. págs. A1-A16.

Ministerio de Comercio Exterior. (2004). Documento explicativo. Obtenido de http://www.sice.oas.org/TPD/USA_C AFTA/Studies/USAexplicativo_s.pdf

Montiel, R. R. (2011). Impacto fiscal por la implementación de las normas internacionales de información financiera en Honduras y propuesta de creación de un programa anual de educación. Obtenido de http://www.tzibalnaah.unah.edu.hn/ bitstream/handle/123456789/1401/ T-MSc00079.pdf;sequence $=2$

\section{Organización para la cooperacion y el} desarrollo economicos . (octubre de 2008). La politica fiscal como herramienta de desarrollo economico en America Latina . Obtenido de https://www.oecd.org/dev/4157832 6.pdf

Por qué son importantes los impuestos. (s.f.). Obtenido de https://taxjustice.somo.nl/es/porque-preocuparse-por-losimpuestos/por-que-sonimportantes-los-impuestos/

Secretaira de Finanzas. (2006). Memoria 2006. Obtenido de http://www.sefin.gob.hn/wpcontent/docs/UPEG/Menu\%20II/Me moria\%20SEFIN/2006.pdf

Secretaira de Finanzas. (2010). Memoria 2010. Obtenido de http://www.sefin.gob.hn/wpcontent/uploads/1970/01/Memoria2010-final_revisada.pdf

Secretaria de Finanzas . (2011). Memoria 2011. Obtenido de http://www.sefin.gob.hn/wpcontent/uploads/2012/12/MemoriaSEFIN-2011-vf.pdf

Secretaria de Finanzas. (2000). Memoria 2000. Obtenido de http://www.sefin.gob.hn/wpcontent/docs/UPEG/Menu\%20II/Me moria\%20SEFIN/2000.pdf

Secretaria de Finanzas. (2001). Memoria 2001. Obtenido de http://www.sefin.gob.hn/wpcontent/docs/UPEG/Menu\%20II/Me moria\%20SEFIN/2001.pdf

Secretaria de Finanzas. (2002). Informe de la liquidación del presupuesto general de ingresos y egresos de la Republica de Honduras ejercicio fiscal año 


\section{ESTRUCTURA DE LA RECAUDACIÓN FISCAL EN HONDURAS: PROGRESIVO O REGRESIVO}

Revista Economía y Administración, Vol. 9, No. 1, 2018

2001. Obtenido de

http://www.sefin.gob.hn/?p=499

Secretaria de Finanzas. (2002). Memoria

2002. Obtenido de

http://www.sefin.gob.hn/wp-

content/docs/UPEG/Menu\%20II/Me

moria\%20SEFIN/2002.pdf

Secretaria de Finanzas. (2003). Informe de la liquidación del presupuesto general de ingresos y egresos de la Republica de Honduras ejercicio fiscal año 2002. Obtenido de http://www.sefin.gob.hn/wpcontent/uploads/2002/12/Liquidacio n-Presupuestaria-2002.pdf

Secretaria de Finanzas. (2003). Memoria 2003. Obtenido de http://www.sefin.gob.hn/wpcontent/docs/UPEG/Menu\%20II/Me moria\%20SEFIN/2003.pdf

Secretaria de Finanzas. (2004). Informe de la liquidación del presupuesto general de ingresos y egresos de la Republica de Honduras ejercicio fiscal año 2003. Obtenido de http://www.sefin.gob.hn/wpcontent/uploads/2003/12/Liquidacio n-Presupuestaria-2003.pdf

Secretaria de Finanzas. (2004). Memoria 2004. Obtenido de http://www.sefin.gob.hn/wpcontent/docs/UPEG/Menu\%20II/Me moria\%20SEFIN/2004.pdf

Secretaria de Finanzas. (2005). Informe de la liquidación del presupuesto general de ingresos y egresos de la Republica de Honduras ejercicio fiscal año
2004. Obtenido de http://www.sefin.gob.hn/wpcontent/uploads/2004/12/Liquidacio n-Presupuestaria-2004.pdf

Secretaria de Finanzas. (2005). Memoria 2005. Obtenido de http://www.sefin.gob.hn/wpcontent/docs/UPEG/Menu\%20II/Me moria\%20SEFIN/2005.pdf

Secretaria de Finanzas. (2006). Informe de la liquidación del presupuesto general de ingresos y egresos de la Republica de Honduras ejercicio fiscal año 2005. Obtenido de http://www.sefin.gob.hn/wpcontent/uploads/2005/12/Liquidacio n-Presupuestaria-2005.pdf

Secretaria de Finanzas. (2007). Informe de la liquidación del presupuesto de ingresos y egresos de la Republica de Honduras ejercicio fiscal año 2006.

Obtenido de http://www.sefin.gob.hn/wpcontent/uploads/2006/12/Liquidacio n-Presupuestaria-2006.pdf

Secretaria de Finanzas. (2007). Memoria 2007. Obtenido de http://www.sefin.gob.hn/wpcontent/docs/UPEG/Menu\%20II/Me moria\%20SEFIN/2007.pdf

Secretaria de Finanzas. (2008). Informe de la liquidación del presupuesto general de ingresos y egresos de la Republica de Honduras ejercicio fiscal año 2007. Obtenido de http://www.sefin.gob.hn/wpcontent/uploads/2007/12/Liquidacio n-Presupuestaria-2007.pdf 


\section{ESTRUCTURA DE LA RECAUDACIÓN FISCAL EN HONDURAS: PROGRESIVO O REGRESIVO}

Revista Economía y Administración, Vol. 9, No. 1, 2018

Secretaria de Finanzas. (2008). Memoria

2008. Obtenido de

http://www.sefin.gob.hn/wp-

content/docs/UPEG/Menu\%20II/Me

moria\%20SEFIN/2008.pdf

Secretaria de Finanzas. (2009). Memoria

2009. Obtenido de

http://www.sefin.gob.hn/wp-

content/docs/UPEG/Menu\%20II/Me

moria\%20SEFIN/2009/files/memoria

$\% 202009-1 . p d f$

Secretaria de Finanzas. (2011). Informe de liquidación del presupuesto general de ingresos y egresos de la Republica de Honduras ejercicio fiscal año 2010. Obtenido de

http://www.sefin.gob.hn/wpcontent/uploads/2011/04/Liquidacio n_2010.pdf

Secretaria de Finanzas. (2012). Informe de la liquidación del presupuesto general de ingresos y egresos de la Republica de Honduras ejercicio fiscal año 2011. Obtenido de http://www.sefin.gob.hn/wpcontent/uploads/2012/04/Informede-Liquidacion-2012.pdf

Secretaria de Finanzas. (2012). Memoria 2012. Obtenido de http://www.sefin.gob.hn/wpcontent/uploads/2013/06/Memoria 2012vNov.pdf

Secretaria de Finanzas. (2013). Memoria 2013. Obtenido de http://www.sefin.gob.hn/wpcontent/uploads/2014/11/Memoria2013-Final1.pdf
Secretaria de Finanzas. (2014). Informe de la liquidación del presupuesto general de ingresos y egresos de la Republica de Honduras ejercicio fiscal año 2013. Obtenido de http://www.sefin.gob.hn/wpcontent/uploads/2014/03/LIQUIDACI ON_PRESUPUESTO_2013_Administra cion-Publica.pdf

Secretaria de Finanzas. (2014). Memoria

2014. Obtenido de http://www.sefin.gob.hn/wpcontent/uploads/2015/12/Memoria2014-FINAL.pdf

Secretaria de Finanzas. (2015). Informe de la liquidación del presupuesto general de ingresos y egresos de la Republica de Honduras ejercicio fiscal año 2014. Obtenido de http://www.sefin.gob.hn/wpcontent/uploads/Presupuesto/2014/ liquidacion/Liquidaci\%C3\%B3n\%202 014.pdf

Secretaria de Finanzas. (2016). Informe de la liquidación del presupuesto general de ingresos y egresos de la Republica de Honduras ejercicio fiscal año 2015. Obtenido de http://www.sefin.gob.hn/wpcontent/uploads/Presupuesto/2015/ liquidacion/Liquidaci\%C3\%B3n\%202 015.pdf

Stiftung, K. A. (2010). Crisis financiera mundial: su impacto economico y social en Centroamérica. Obtenido de http://www.kas.de/wf/doc/kas_189 16-1522-4-30.pdf?100305224452 


\section{ESTRUCTURA DE LA RECAUDACIÓN FISCAL EN HONDURAS: PROGRESIVO O REGRESIVO}

Revista Economía y Administración, Vol. 9, No. 1, 2018

Tasa de Seguridad Poblacional. (2016). Portal

de Transparencia. Obtenido de

http://www.tasadeseguridad.hn/ace

rca 
ESTRUCTURA DE LA RECAUDACIÓN FISCAL EN HONDURAS: PROGRESIVO O REGRESIVO

Revista Economía y Administración, Vol. 9, No. 1, 2018 